\title{
Surface layers analysis of bronze artifacts by means of laser spectroscopy techniques
}

\author{
I. Żmuda-Trzebiatowska* and G. Śliwiński, \\ The Szewalski Institute of F-FM, Polish Academy of Sciences, Photophysics Dept., \\ 14 Fiszera St., 80-231 Gdansk, Poland
}

Received May 13, 2011; accepted June 03, 2011; published June 30, 2011

\begin{abstract}
Advantages of the complementary use of spectroscopic techniques are exemplified by the analysis of a historical bronze mortar from XV c. performed as part of the running collection conservation project by the National Museum in Gdansk. The bulk material and surface layers are analyzed by means of the XRF and $\mu$-Raman techniques. Quasi-nondestructive LIP (Laser Induced Plasma) spectroscopy delivers additional data on the elemental composition and is applied also for stratigraphic sampling across the surface layers.
\end{abstract}

A detailed understanding of the environmental impact on historical metal artefacts is of considerable importance for their preservation. In most cases, the poor state of historical metal objects and collections being a significant part of our cultural heritage results from prolonged exposure to adverse environmental conditions [1]. Recently, systematic research on historic collections and case studies show that the combination of spectroscopic and optical techniques for elemental, compositional, and structural analysis enhance greatly the reliability of results [2-3]. Moreover, non-destructively operating instruments allow us to keep the impact on valuable and precious objects extremely low.

This paper presents the results of analysis of the material and patina of the historic bronze mortar (Fig. 1) by means of complementary spectroscopic methods, which ensure reliable characterization of the object.

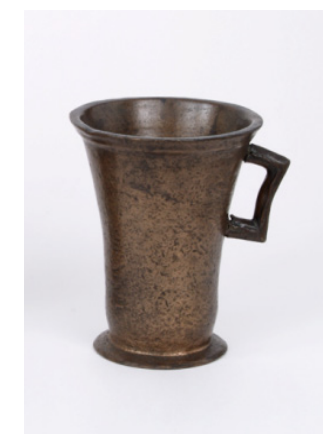

Fig. 1. The bronze mortar (XV c.).

The bronze mortar (XV c.) produced by casting has a bell shape and a rectangular handle - see Fig. 1.

*E-mail: izmuda@imp.gda.pl
Typically, the gothic mortars were decorated with reliefs based on architectural motives. The object under investigation originates most probably from Gdańsk and represents a modest version of the dish characterized by a smooth, not ornamented coat. Dishes of this type were popular in Northern Europe in the fifteenth century. The mantle just above the foot is slightly bellied with a little horizontal crack visible on the surface. The entire surface is covered with a homogeneous layer of brown patina with the exception of the foot edge. The light reflection on the surface may originate from the protection layer applied during previous conservation. Small traces of a greenish-coloured patina are present on the foot reverse and the handle, too.

An elemental analysis of the object was carried out non-invasively by means of an X-ray fluorescence spectrometer (XRF) completed at IF-FM PASci. The spectrometer X-ray tube IS601.5 (Italstructures) used for excitation has produced an excitation beam collimated to a spot of $4 \mathrm{~mm}$ in diameter. The tube was operated at $50 \mathrm{kV}$ and $1 \mathrm{~mA}$, and ensured detection of elements in the range from $K$ (19) to $U$ (92). During measurements an accumulation time of 120 s for recording of each spectrum was applied.

The XRF results were supplemented by the LIBS data in order to increase the level of confidence of the detected elements. The LIB spectra were recorded under pulsed excitation with an Nd: YAG laser (Quantel) operated at $1064 \mathrm{~nm}$ and energy density of $2 \mathrm{~J} / \mathrm{cm}^{-2}$. The plasma light was dispersed by the 0.5 monochromator SR-303i (Andor Tech.) equipped with a grating (600 grooves $/ \mathrm{mm})$ and coupled to the time-gated ICCD camera DH 740 (Andor Tech.). Spectra were recorded in the wavelengths range of $200-800 \mathrm{~nm}$ at a resolution of $0.3 \mathrm{~nm}$, and the applied camera time gate width and delay were equal to $10 \mu$ s and $1 \mu \mathrm{s}$, respectively.

For identification of the patina content, the $\mu$-Raman spectra were recorded using the spectrometer Invia (Renishaw) coupled with a confocal microscope (magnification 50x) and equipped with a $785 \mathrm{~nm}$ diode laser. Spectra were acquired in the full spectral range from 100 to $3200 \mathrm{~cm}^{-1}$ at a resolution of $2 \mathrm{~cm}^{-1}$. 


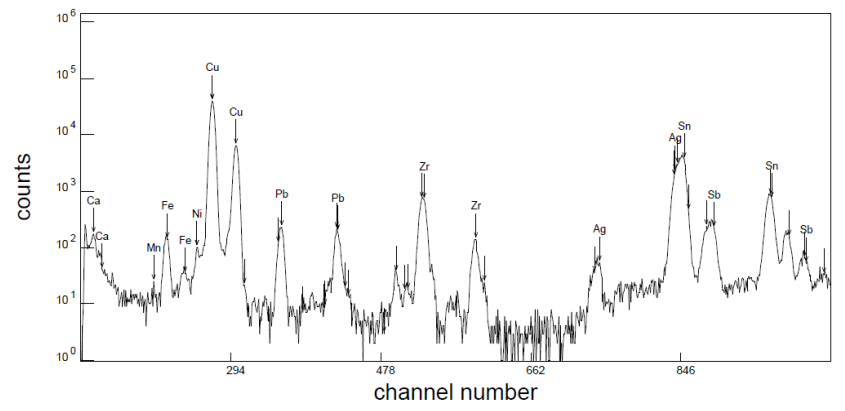

Fig. 2. The XRF spectrum of the mortar surface.

In the XRF spectrum obtained for the mortar surface the following elements are identified: $\mathrm{Sn}, \mathrm{Fe}, \mathrm{Ni}, \mathrm{Cu}, \mathrm{Pb}$, $\mathrm{Zr}, \mathrm{Ag}, \mathrm{Sb}$, and the spectrum is shown in Fig. 2 [4]. The $\mathrm{Zr}$ spectral lines originate from the internal collimator of the applied X-ray detector. The elements: tin, copper and lead are main components of the tin-lead bronze, the iron and nickel originate from contaminants, and the presence of silver and antimony is due to impurities. Peaks of $\mathrm{Ca}$ may derive from the surface contaminant calcite.

a)
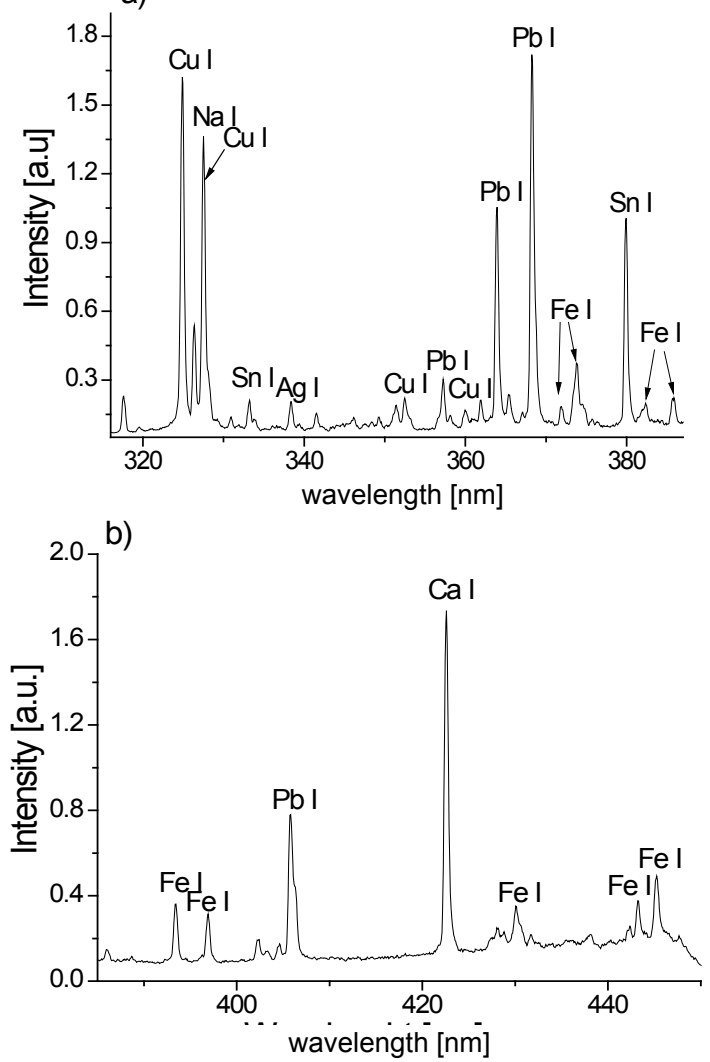

Fig. 3. The LIB spectra of selected spectral bands recorded under excitation at $1064 \mathrm{~nm}$ for the reverse side of the mortar feet.

Also the structure of the most characteristic bands in the LIBS spectra and qualitative analysis of the peaks indicates that the most numerous and strongest peaks originate from $\mathrm{Cu}$ and $\mathrm{Pb}$. In agreement with the XRF data, LIBS confirms the presence of main elements such as copper, lead, silver, and iron. Moreover, the elements: calcium, carbon, and sulfur (not shown in Fig. 3) are revealed by the LIBS analysis, too.

The presence of a patina and its layer thickness can be concluded from the LIB stratigraphic sampling of the surface layers. The results are shown as dependence of intensities related to maximal values measured, of the spectral lines of $\mathrm{Pb}$ at $357.25,363.93$ and 368.32 on the successive laser pulse number - see Fig. 4(a).
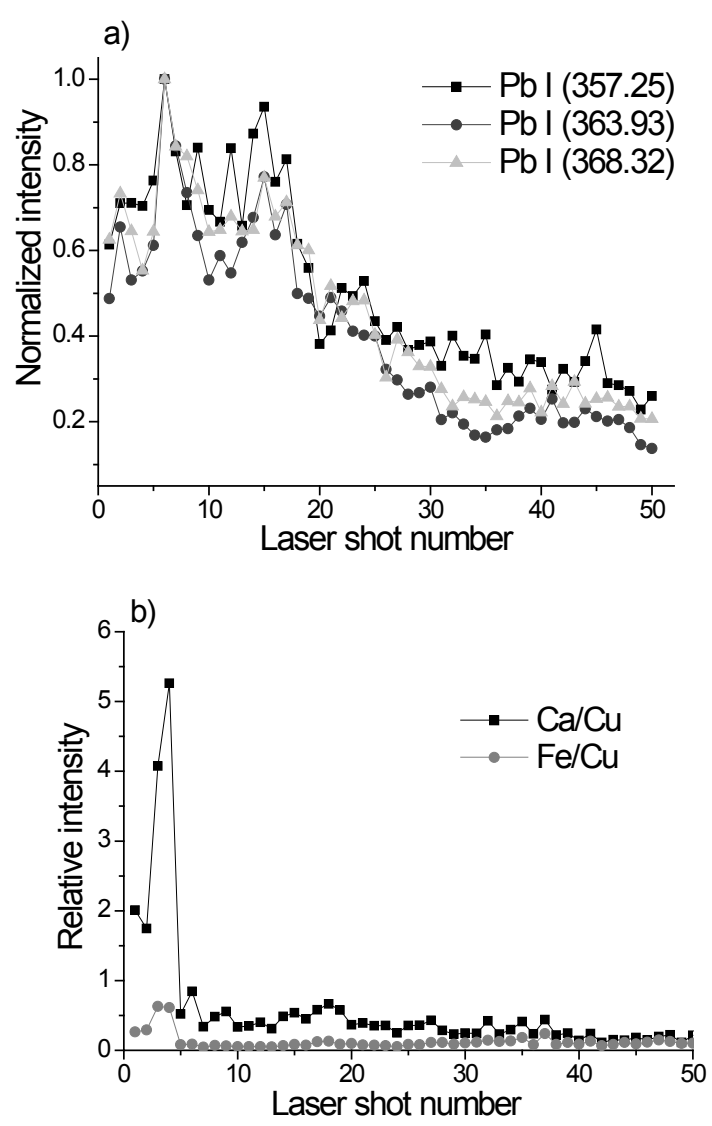

Fig. 4. The intensity of the LIB spectral lines vs. laser pulse number observed during stratigraphic sampling of the surface layers; dependence for prominent $\mathrm{Pb}$ lines (a), and for surface impurities (b).

At the beginning of irradiation (pulse number $<5$ ), the uppermost, light reflecting layer is penetrated and the $\mathrm{Pb}$ signal increases. Next, (pulse number <15) the $\mathrm{Pb}$ intensities remain roughly constant during the patina layer removal. Assuming the ablation rate of about 2-3 $\mu \mathrm{m} /$ pulse known from previous measurement, the layer thickness in the range of about $3 \mu \mathrm{m}$ can be estimated [5]. During prolonged irradiation (pulse number $>15$ ) the intensity of $\mathrm{Pb}$ lines decreases to the level characteristic 
for the bulk material. In Fig. 4(b) the line intensities of $\mathrm{Ca}$ $\mathrm{I}$ at $612.16 \mathrm{~nm}$ and $\mathrm{Fe} \mathrm{I}$ at $382.42 \mathrm{~nm}$ are related to the intensity of the most prominent copper line $\mathrm{Cu} \mathrm{I}$ at $510.56 \mathrm{~nm}$, as $\mathrm{Cu}$ is the main element/component of the bulk material. The complete removal of elements $\mathrm{Ca}$ and $\mathrm{Fe}$ due to several laser pulses lead to doubtless identification of this surface coverage on the protective paint layer [6].

The Raman spectrum of the surface coverage taken from the reverse side of the object base, with spectral bands assigned by the Spectral ID software, indicate on strong fluorescence of the protective paint layer, and therefore its compound only, i.e. the phthalate (PDAP) polymer, can be identified - see Fig. 5. This compound is most probably used as a base for paint production. Its local uncovering is required in order to extract a microsample for analysis and recording of the Raman spectra of the patina. With the permission of the collection owner the authors believe to continue work on this subject soon.

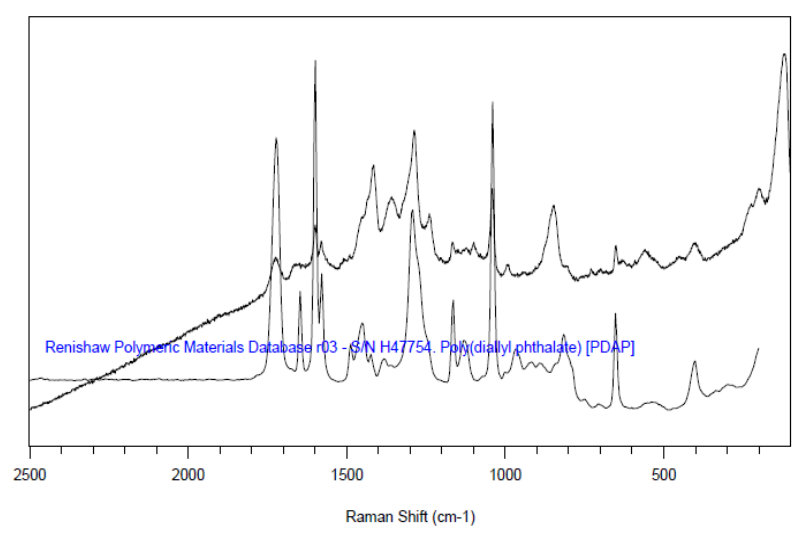

Fig. 6. The Raman spectrum of the patina sample and the reference spectrum of the polymer [PDAP].

In summary, the results confirm the usefulness of the complementary XRF and LIBS measurements to determine the elemental composition of surface layers on historic metal objects.
The XRF and LIPS data support the component analysis by means of the Raman technique, which in turn allows to indentify surface layers such as patina, contaminants and protective coating. Apart from obvious advantages of the XRF technique, such as the possibility of in-situ measurements, almost absolutely non-destructive operation because no sample extraction (preparation) is required, and immediate result of the analysis, the measurement range of lighter elements only up to $\mathrm{Z}>19$ can represent limitation in some cases. To overcome this, the LIBS technique, which can examine the elemental composition in a wider range, can be applied. However, in the case of precious historical objects a rigorous requirement of non-destructive testing can disqualify this technique because of the micro-damage due to surface ablation and removal of $\mu$ grams of the investigated material.

This work was supported by the research program O3T2/2010 of the IF-FM. The authors thank Dr. M. Sawczak for technical assistance and fruitful discussion. Many thanks are also due to Mrs. A. Kriegseisen and Mrs. A.Fietkiewicz from the National Museum in Gdańsk for supplying historical metal objects for this study.

\section{References}

[1] A. Iwulska, I. Traczyńska, R. Jendrzejewski, M. Sawczak, G. Śliwiński, A. Kriegseisen, Laser in the Conservation of Artworks VIII, (CRC Press, Taylor \& Francis Group, 2010).

[2] M. Sawczak, A. Kamińska, G. Rabczuk, R. Jendrzejewski, G. Śliwiński, Appl. Surf. Sci. 255, 5542 (2009).

[3] V. Desnica, K. Skaric, D. Jembrich-Simbuerger, S. Fazinic, M. Jaksic, M. Pavlinic, I. Peranic, M. Schreiner, Appl. Phys. A 92, 19, (2008)

[4] R. Cesareo, J. Phys., 76, 313, (2011)

[5] Ł. Ciupiński, E. Fortuna, H. Garbacz, A. Koss, K.J. Kurzydłowski, J. Marczak, J. Mróz, T. Onyszczuk, A. Rycak, A. Sarzyński, W.Skrzeczanowski, M.Strzelec, A. Zatorska, G.Z. Żukowska, Sensors 10, 4926-4949, (2010).

[6] H. Garbacz, E. Fortuna, Ł. Ciupiński, K.J. Kurzydłowski, A. Koss, J. Mróz, A. Zatorska, K. Chmielewski, J.Marczak, M.Strzelec, A. Rycak, W. Skrzeczanowski, Laser in the Conservation of Artworks VIII, (CRC Press, Taylor \& Francis Group, 2010). 